\title{
Learning from the Past Ten-Year Effects of Economic Cooperation Framework Agreement (ECFA)
}

\author{
Kemo Chen ${ }^{1, *}, \dagger$, Linfeng Jiang ${ }^{2,}{ }^{*}, \dagger$, Haohong Liang ${ }^{3, *}, \dagger$, Weixi $\mathrm{Su}^{4,}{ }^{*}, \dagger$, Yuyuan \\ Wang ${ }^{5, *}, \dagger$
}

\author{
${ }^{1}$ China Agricultural University, Beijing, China \\ ${ }^{2}$ East China University of Science and Technology, Shanghai, China \\ ${ }^{3}$ The University of Melbourne, Melbourne, Australia \\ ${ }^{4}$ Albert-Ludwdig-Universität Freiburg, Freiburg.i. Br, Germany \\ ${ }^{5}$ Beijing Normal University - Hong Kong, Baptist University United International College, Zhuhai, China \\ *Corresponding author. Email: ${ }^{1}$ chen_km@cau.edu.cn, ${ }^{2}$ jlf1061794517@163.com, ${ }^{3}$ haohong@student.unimelb.edu.au, \\ ${ }^{4}$ weixi.su@pluto.uni-freiburg.de, ${ }^{5}$ q030024274@mail.uic.edu.cn \\ These authors contributed equally.
}

\begin{abstract}
This paper aims to study the impact of ECFA on the import and export of goods between the mainland in China and Taiwan, which is of great significance to explore its improvement measures and future development trend. To figure out the problem, this paper focused on the two stages of the development of ECFA and the background of each stage and the wide influence and outstanding contribution of ECFA. The method has been taken advantage of in this paper to testify the Hypotheses. Thus, through the data analysis, the paper found out that both tariffs and politics were vital elements to determine China mainland's exportation and importation. It also means that the improvement of political environment and reduction of tariffs in ECFA can prompt the cross-strait trades of China mainland. The research concludes that ECFA has improved Chinese importation, which is derived from increasing exportation, tariffs exemption, and relieving political tension, which is brought by the sign of ECFA. Other limitations and context will be discussed later in the paper.
\end{abstract}

Keywords- ECFA, China; Taiwan, free trade agreement, T-text, F-text.

\section{INTRODUCTION}

There is tremendous concern about the reinforcement of ECFA (Cross-Straits Economic Cooperation Framework Agreement). With the apparent worse political relationship between mainland China and Taiwan, the debate about whether the prolonging this trade agreement has been rising, not only because of disastrous mutual trust but also its efficacy. Some scholars and politicians have doubted that the advantages of maintaining ECFA are mere, and the accretion of trade between mainland China and Taiwan resulting from these trade agreements can be neglected. To make a sound standpoint within this heating debate, it is necessary to figure out what ECFA surely is.

ECFA is a trade and investment framework agreement, which is necessary for a comprehensive FTA. The main component of this agreement is the early harvest list, containing 557 items of commodities opting to Taiwan and 268 items of commodities opening to mainland China $[1,2]$. According to the agreement, the tariff to the goods within the early harvest list will be reduced to 0 . Besides, other elements, be they Certificate of Origin, enhancement of investment, and agreement to non-financial service, are included in ECFA. This kind of framework agreement should be put on records in WTO and should be reviewed in 10 years after its signing if there is no further development exists. With the outbreaking of the upheaval against the cross-strait agreement on trade in services in 2014, which is called the Sunflower Event, the development of the ECFA and further negotiation about the comprehensive free trade agreement has been de facto stagnated. This agreement was signed in the year of 2011. This year is the ten years after signing. Thus, the reviewing of the necessity of maintaining the agreement of abolishing it seems 
inevitable. In this paper, reviewing the early harvest list of goods will be the focus.

Based on the record of the past ten years, the value of commodities within the early harvest list accounted for about $20 \%$ of cross-strait trade, which is a small part. This phenomenon has raised the doubt of some scholars that the positive effect of EFCA is not as strong as it has been promulgated. Besides, after both mainland China and Taiwan participated in ITA (Information Technology Agreement), some people stated that the effect of ECFA had been attenuated because this agreement proposes to lower all taxes and tariffs on information technology products by signatories to zero, which account for the largest proportion of Taiwan's overall export. Because the classical platform of labor division between mainland China and Taiwan is that Taiwan serves as R\&D and exporter of intermittent goods, and mainland China functions as the resemble and the exporter of consuming products. Thus, whether this kind of collaboration related to ITA has diluted the effect of ECFA remains unanswered.

This paper aims to contribute to the resolution of these debates and orients to the research question: has ECFA enhanced the trade between mainland China and Taiwan. Moreover, a peripheral question should also be considered, which did the trade conflict related to ECFA impeded the effectiveness of EFCA. To deal with these research questions, the first step of this paper is to review present existing literature about the topic of ECFA and International trade. After carefully reviewing and generating necessary theories and facts, a specific quantitative analysis model should be formulated and examined. With the help of the second-hand data, which are abstracted from authoritative databases, and the model, the qualitative results will be interpreted. In advance, it might be posited that ECFA will enhance interregional trade. After the qualitative analysis, this hypothesis could either be undergirded or supported. At the very end of this essay, some political suggestions based on our previous analysis will be initiated to provide useful thought and perspectives to the future development of ECFA, maintained or abolished.

\section{LITERATURE REVIEW}

\subsection{Content of ECFA}

All in all, the changes in ECFA can be divided into two sections, "early harvest" and "follow-up".

In the beginning, the Early Harvest Program for trade in goods and services will be implemented. By signing the Cross-strait Service Trade Agreement, mainland China hoped further enhanced trade and investment relations across the Taiwan Straits. It established a cooperation mechanism conducive to economic prosperity and development across the Straits. Later,
ECFA has ushered in landmark progress, often referred to as the "follow up" stage. In 2017, Song et al. said, besides goods trade, service also is one of the contents in agreement [3]. Taking telecommunications to open up a large area as an example, China mainland provides policies to support Taiwan investors like holding shares higher than the WTO rules, lowering the qualification recognition of enterprises, etc. [4]

\subsection{Background Of ECFA}

During "early harvest", in May 2008, the relationship between the two sides reached a historical turning point, and negotiations between the two sides resumed, creating a rare opportunity for cross-strait economic and trade exchanges and cooperation. It was the urgent desire of people from both sides of the Taiwan Straits, especially those from all walks of life in Taiwan, to integrate into the trend of regional economic cooperation in the world as soon as possible, to jointly deal with the sudden fall of the international financial crisis and to speed up the establishment of the cross-straits economic cooperation mechanism [5].

At that time, the vigorous development of global, regional economic cooperation in Taiwan's economy was under pressure of being "marginalized." The outbreak of the international financial crisis also made the island's economic growth sluggish, there is an urgent need for Taiwan to seek entry points into regional economic cooperation and new growth points to boost the island's economy. At the same time, the realization of the normalization of cross-strait economic relations has become the common sound of people across the Straits. In June 2010, under the joint efforts of both sides of the Taiwan Strait, the ECFA came into being [6].

In the second period, with the development and deepening of the international economy, globalization and integration, and the constant adjustment and improvement of the industrial structure, the demand of enterprises and individuals for services has become more and more specialized and refined. The proportion of the service industry in the national economy has been increasing, service trade in global trade, the share of the total volume of trade, continues to increase, its weight, the importance of increasingly prominent. Under this background, the two sides of the Taiwan Strait signed the agreement on trade in services, thus conforming to the development trend of international trade [3].

\subsection{Development of ECFA}

The development of ECFA is continuous, and it is constantly improved and expanded in the cross-strait trade.

When papers mention ECFA, the fundamental rule established by the ECFA is the Cross-Strait Service 
Trade Agreement. In the course of its development came the cross-strait customs cooperation agreement, the cross-strait investment protection, and promotion agreement, and the Cross-Strait Service Trade Agreement. In January 2010, the two sides exchanged views on the title, basic structure, and establishment of consultation and working mechanism of the Cross-Strait Service Trade Agreement. They reached a consensus on a number of issues. June 29, 2010, cross-Strait trade policy has reached a historic turning point, with Association for Relations Across the Taiwan Straits chairman Chen Yunlin and Straits Exchange Foundation Chairman Chiang Pin-kung signing the Cross-Strait Service Trade Agreement and the Cross-Strait agreement on intellectual property rights protection, respectively. In the following five years, the two sides held two securities and Futures Regulatory Cooperation meetings. By the end of November 2017, there were only three rules of implementation based on the Cross-Strait Service Trade Agreement. Of those rules, after the "anti-trade in services" movement in Taiwan in 2014, the Cross-Strait Service Trade Agreement has not yet come into effect, which cannot but be said to be a negative influence on the fulfilment and implementation of the Cross-Strait Service Trade Agreement. Of course, in addition to the Cross-Strait Service Trade Agreement, other agreements on exchanges and cooperation between the two sides of the Taiwan Strait are also constantly being followed up, such as transport (air and sea), postal services, food safety, financial cooperation, mutual legal assistance, fisheries services, quarantine inspection of agricultural products, standard metrological inspection and certification, protection of intellectual property rights, medical and health, nuclear power safety, meteorological and Seismic Monitoring and taxation, the co-operation in this area has also involved, in different ways, some of the economic co-operation issues regulated in the Cross-Strait Service Trade Agreement [7].

\subsection{Attribute of ECFA}

Compared to other FTAs, ECFA is not a treaty between countries but a domestic economic integration agreement in a country whose content is regulated and adjusted by WTO rules. ECFA has shown distinctive "cross-strait characteristics" in terms of name, subject, adjustment objects, basic principles, and implementation mechanisms [8].

Chang believed that the signing of the ECFA was mixed with complicated political and economic issues [9]. As far as the current legal nature is concerned, it should be attributed to the transitional agreement of FTA [6]. It provides a normative basis for the plans, issues, and scheduled progress of future substantial trade liberalization across the Straits. The final establishment of a cross-strait "free trade area" still must rely on substantive economic and trade agreements such as the
Comprehensive Economic Cooperation Agreement (CECA) to determine the rights and obligations between the two parties in this "free trade area."

\subsection{Influence of ECFA}

Steady growth in cross-strait trade: In 2011, Lee et al. showed ECFA liberalization increased the seaborne trade volume flows because of the correlation between shipping demand variations and trade liberalization derived by their models [10]. Since the signing of ECFA, the development of cross-strait trade has made remarkable achievements. According to statistics from the General Administration of Customs of Mainland China, the total value of cross-strait imports and exports from 2009 to 2019 increased from US\$106.23 billion to US $\$ 228.08$ billion, an average annual growth rate of $7.9 \%$, and exceeded the US\$200 billion mark in 2018. Up to now, Taiwan ranks 7 th among the mainland's trading partners, accounting for about $5 \%$ of the mainland's total imports and exports and is also an important source of imports for the mainland (ranking 4th). As far as Taiwan is concerned, in 2017, Zheng et al. said, 10-years performance analysis of ECFA show the good situation of cooperation which is both straits have grown steadily, Taiwan's investment in the mainland is deepening, and the mainland has become the biggest export market and source of trade surplus [11]. Overall, the scale of cross-strait trade has expanded rapidly, and Taiwan's trade surplus with the mainland has also maintained a relatively high level.

The regional layout of Taiwanese capital in the mainland gradually extends: The signing and implementation of ECFA have put the cross-strait economic and trade cooperation into an institutionalized track. The scale of Taiwan's investment in the mainland has continued to develop steadily. It is precisely because of Taiwan's extensive commercial presence on the mainland that these Taiwan-funded enterprises will inevitably maintain close business contacts with the island's parent company, especially in the areas of the introduction of intermediate products and technical support, which will promote cross-strait relations, forming a close economic and trade cooperation relationship.

Cross-strait trade boosts Taiwan's economic development: Trade exports are the main driving force behind Taiwan's economic growth. The trade surplus is an important force driving Taiwan's economic growth, and it strongly supports Taiwan's stable economic growth. Thus, in this way, Mainland's substantial reduction or exemption of tariffs on commodities under the ECFA has reduced corporate costs and strengthened the market competition of Taiwan-funded enterprises. It also provides the impetus for the development of new markets. 
Cross-strait trade promotes the development of mainland foreign trade: The mainland has increased its production and export capabilities by importing key raw materials and components from Taiwan, thereby promoting exports to other countries and regions. With the help of Taiwanese capital, the mainland has become more actively involved in the international division of labor, connecting the European and American markets through the "two-heads outside" business model, making the mainland an important link in the Asian production network and even the global value chain. On top of that, in 2013, Xuan said the Chinese completed industry chain and Taiwanese Hi-Tech industry could be complementary in production [12]. Taiwan's high-tech industries are relatively developed, and Taiwan-funded enterprises, as carriers and channels for technology diffusion, have supported the development of the mainland's high-tech industries to a certain extent. This has laid a solid foundation for the mainland's economic transformation and coordinated development. A broader market also means that more employment opportunities can be provided. On top of that, in 2017, Zheng and Hua said, the policy of deeper the reform and opening up from mainland, and the economic restructuring and up-gradation and the Belt and Road Initiative can expand in the international market [4]. Therefore, comprehensively implemented and deepened ECFA is very vital since it could improve the local supply chain [3]. Overall, in 2020, Bai and Liu said that ECFA benefits both Taiwan and China's mainland. For China's mainland, industry transformation and upgrade are accelerated in many aspects. For Taiwan, small and medium-sized enterprises (SME) and local farmers and fishermen are supported [13]. These studies all show that ECFA is beneficial to both economies. However, these studies ignore the effects when conflicts of trade outbreaks, what will happen to the trade volume.

\section{METHODOLOGY}

\subsection{Analysis}

To resolve this controversial dispute, this paper will use quantitative methods to provides some potentially useful insights. Thus, the first step is to formulate hypotheses. The hypotheses are as follows.

H1: The reduced tariff contributes to the overall import of mainland China from Taiwan.

H2: The political atmosphere toward ECFA affects the cross-strait trade.

H3: ECFA is unilateral advantageous or mutually beneficial.

H4: The unique trade pattern of "Investor-factory" has a profound effect on diluting the effect and welfare conducted by ECFA.
The first step is to conduct a meaningful data preparation (consolidation, cleaning, transformation, and reduction) to testify these hypotheses. The time scale of relevant data should be from 2011(the first year of enforcing ECFA) to 2020(the last full-ended calendar year). To make a comparative analysis and to eliminate the effect of the exchange rate, the monetary value of the data, which could be gauged, should be calculated in US dollars. The kinds of relevant data, which are needed to collect, are the overall Import of mainland China from Taiwan, overall export of mainland China to Taiwan, reduced tariff according to ECFA, index of the political atmosphere, and export of Taiwan to other main economics. However, some difficulties must be carefully dealt with. The first one is that the political atmosphere is a subjective and qualitative matter but obliged to be quantified measured. The solution is to use a dummy variable. The standard of the dummy is if there is the development of discussion of ECFA. Thus, the years from 2011 to 2015 are 1, and the years from 2016 to 2020 are 0 . The next question is the data of export from Taiwan to other main economics are numerous. The answer to this question is sampling. According to the annual report of Taiwan's commerce chamber, the biggest destination of Taiwan's electronic products (besides mainland China), which are major export components of Taiwan, is the United States. Thus, this paper will take advantage of the export from Taiwan to the USA. Besides, the methods of the statistic of customs of mainland China and Taiwan toward ECFA and cross-strait trade are different. Thus, this paper will focus on the statistics from mainland China if there are conflicts. The resource of Data is the official Website of ECFA, which will provide regular review of the executive of ECFA and economics departments of mainland China and Taiwan's governments.

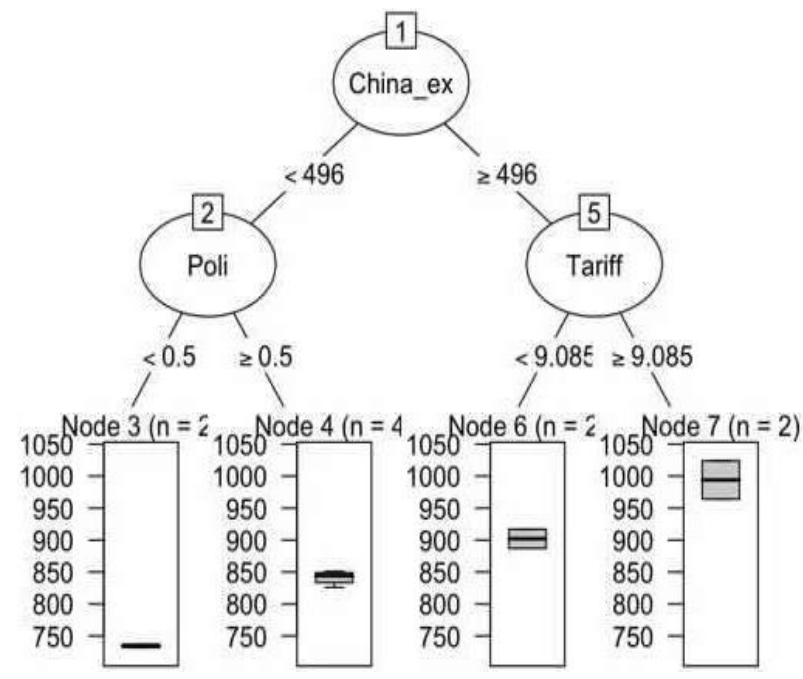

Figure 1. Variables for Chinese Exportation

The step before the end is to formulate a concrete linear regression model. Since there could be some interactive relationship between the independent 
variables, it is imperative to design a model with factors that imply interaction's potential relationship. The final step is to run the formulated model within $\mathrm{R}$ and get the result. The predefined confident interval for Student- $t$ Test and F-test should be $95 \%$. Furthermore, the goddess of fit of this model will be interpreted by the R-square number. The intended threshold of $\mathrm{r}^{\wedge} 2$ has been set to be over $80 \%$. To ensure the robustness of this regression model and avoid perfect problems such as multicollinearity, heteroscedasticity, and autocorrelation, which the Gauss-Markov Theorem requires, some previous statistical tests, such as White test has been made. As a result, this model can be performed.

\subsection{Result}

According to the modeling, In the regression tree (see Figure 1.) with machine learning, the Chinese magnitude of importation is correlated to exportation, tariffs exemption, and political condition.

Table 1. Result of Linear Regression Model

\begin{tabular}{|c|c|c|}
\hline & Dependent Variable & \\
\hline \multirow{3}{*}{ China_ex } & China_in & sig \\
\hline & 3.624 & $* *$ \\
\hline & $(0.643)$ & \\
\hline \multirow[t]{2}{*}{ Poli } & 1.297 .874 & \\
\hline & $(952.151)$ & \\
\hline \multirow[t]{2}{*}{ Tariff } & 219.456 & $* *$ \\
\hline & $(40.191)$ & \\
\hline \multirow[t]{2}{*}{ China_ex:Poli } & -1.250 & \\
\hline & $(2.127)$ & \\
\hline \multirow[t]{2}{*}{ China_ex: Tariff } & -0.309 & $*$ \\
\hline & $(0.076)$ & \\
\hline \multirow[t]{2}{*}{ Poli : Tariff } & -88.361 & \\
\hline & $(135.493)$ & \\
\hline \multirow[t]{2}{*}{ China_ex: Poli: Tariff } & 0.008 & \\
\hline & $(0.301)$ & \\
\hline Constant & -1489.689 & $* *$ \\
\hline \multirow[t]{5}{*}{ Observations } & 10 & \\
\hline & 0.998 & \\
\hline & 0.990 & \\
\hline & $9.111(\mathrm{df}=2)$ & \\
\hline & $128.621(\mathrm{df}=7 ; 2)$ & $* * *$ \\
\hline Note: & $* \mathrm{p}<0.1 ; * * \mathrm{p}<0.05 ; * * * \mathrm{p}<0.01$ & \\
\hline
\end{tabular}

In Table 1, each unit change of independent variable will bring corresponding unit change on the dependent variable and its Std. err (Standard Error) means standard deviance between evaluated parameter and constant value. Smaller Std.err suggests that more precise value. $\mathrm{T}$ values are used to measure the regression. The higher value means the fitter data to the regression line. Pr (> $|t|)$ is the P-value of 5\% two-sample t-test. This value closer to 0 means the data is reliable. At the raw Chine_ex means one more unit of Chinese exportation could bring 3.624-unit Chinese importation, and the meaning of other columns are similar to the intercept.

In linear regression, $\mathrm{r}^{\wedge} 2$ is used to measure the fit of variables, ranging from 0 to 1 , and 0 means no variance has been explained; meanwhile, 1 means it has all been explained. Normally, $\mathrm{r}^{\wedge} 2>0.9$ could be considered that data are extremely strong relevant.
The outcome of $\mathrm{r}^{\wedge} 2$ is 0.99 , which shows that importation is highly correlated with exportation and tariffs exemption.

\subsection{Discussion}

The data analysis shows that both tariffs and political factors are very vital elements to the amount of China mainland's exportation and importation, which also means that the improvement of political environment and reduction of tariffs can prompt the cross-strait trades of China mainland through more unrestricted trade. Although the character of ECFA is not a treaty and it is an agreement, which leads to ECFA does not contain political content but still are greatly influenced by the political atmosphere from cross-strait. Since the scale of exportation and importation of the mainland is an important part of cross-strait trades, the sign of ECFA indeed has real improvements on China mainland in cross-strait trades. The previous hypothesis is precise and appropriate.

The influence of signing ECFA also has many commons compared to the current study and previous literature review. Firstly, the reductive tariffs cause the growing amount of exportation and importation in cross-strait trades, just as Bai said this could greatly flourish free trades and enlarge the more variable fields of goods that two straits are willing to exchange. The structure of industries will be optimized for both sides [13]. Then, cross-strait trade is steadily growing because according to the export promotion effect of tariffs reduction, both sides can bring their power into full pay and use their different advantages to impetus mutual trades. Subsequently, the structure of industries will be optimized for there are much higher needs to expand the border market or better quality of high-tech from both sides. This conclusion also has universality in other cases. When tax relief is increasing to one country, the much higher number of exportation and importation is more possible. Compared to the result from the data analysis, the conclusion is similar to the previous study that the tariffs have negative correlations with the trade between cross-strait. In this way, to improve the further development of ECFA, the much larger fields are needed to be tax-free for both sides to gain greater trades surplus, just as Song postulated [3].

Secondly, the political issues and environment also have very focal effects on the cross-strait trades. In other words, the circumstance of ECFA reflects the condition of the cross-strait political relationship. Tsung pointed that the political atmosphere was relaxed and kind, the cooperation would be deeper, and the ECFA would positively progress [13]. On the contrary, the cooperation will be strongly limited, and the condition of ECFA will be deteriorating. The data analysis above proves that the political atmosphere in Taiwan and the political relationship with both sides also significantly influence 
the cross-strait trades, which is similar to mentioned papers. Since the theory of the political superstructure affects the economic base, which strongly proves that the political elements are crucial to economic activities, including commercial agreements. As a result, the conclusion has few commons with the previous study that the political factors positively correlate with the trade between cross-strait. In this aspect, we should pay more attention to the political environment between both straits to improve the ECFA.

\section{CONCLUSION}

ECFA is the first institutional economic cooperation agreement between the two sides of the strait. The signing and implementation of other agreements profoundly impact the promotion of cross-strait economic and trade cooperation. Overall, the positive contribution of ECFA outweighs its potential negative impact. The development of ECFA is a gradual and tortuous process.

The base decides the base and superstructure. The harmonious development of Cross Strait relations cannot be achieved without trade exchanges. The ECFA can be seen as the link of economic, cultural, and political ties between the two sides. The current trend of economic globalization is facing serious challenges. The Taiwan authorities cannot rely on their own power to protect themselves, and the Chinese mainland, as a major trading nation, has been actively seeking win-win cooperation, with the rise of trade protectionism in Western developed capitalist countries, various power policies under the pretext of anti-dumping and anti-monopoly threaten the development of World Economic Integration.

From the perspective of long-term Dynamic Effects, the establishment of ECFA will improve the welfare level of both sides of the Taiwan Straits, benefit the economic growth of both sides of the Taiwan Straits, improve the terms of trade with Taiwan, and expand the total volume of Taiwan's import and export trade. It will help Taiwan build a better, stable, and predictable business environment for cross-strait trade. There are many ways to alleviate the crisis of Taiwan's economic marginalization. For instance, more preferential policies should be given to attract more foreign investment into Taiwan and set up the operation headquarters.

From the perspective of cross-strait import and export trade, under the influence of ECFA, cross-strait trade continues to grow steadily. As far as Taiwan is concerned, the mainland is currently its largest trading partner and Taiwan's most important export market and source of trade surplus. At the same time, the regional distribution of Taiwanese capital in the mainland is gradually expanding, and the industrial layout in the mainland is also increasingly optimized. It is said that the
Taiwanese capital has tended to a steady-state trend in mainland China.

Thanks to ECFA, cross-strait economic and trade cooperation has gone through a fruitful decade, and both the mainland and Taiwan have benefited from it. For Taiwan, cross-strait economic and trade cooperation can drive economic growth on the island, support small and medium-sized enterprises, bring dividends to farmers and fishermen, and help Taiwanese businessmen open up international markets. For the mainland, cross-strait economic and trade cooperation can promote the transformation and upgrading of mainland industries. Promoting balanced regional development and creating jobs have all played a positive role. The results of ECFA are hard-won and need to be cherished and maintained by compatriots on both sides of the strait.

In fact, the degree of ECFA is to pursue economic interests and has far-reaching significance for cross-strait financial cooperation. In the longer term, the scope of negotiations, the main issues, and the timing of the promotion of cross-strait services trade agreements, as well as the actual negotiation and signing of cross-strait services trade agreements, are regulated in the ECFA text, it will have a comprehensive and profound impact on the further development of cross-strait financial cooperation. In the short term, the issue of opening up the financial sector has been included in the early harvest arrangement so that the cross-strait financial sector can enjoy the preferential benefits of market opening earlier, and the pace of cross-strait financial exchanges and cooperation will be further accelerated. However, due to the obvious asymmetry of the early harvest list of the cross-strait financial services industry, the imbalance of cross-strait financial exchanges will be strengthened at this stage. It is worth mentioning that because the ECFA is a gradual way to promote economic and financial integration between the two sides, its effect will be gradually manifested in the process of cross-strait consultation and practice.

\section{ACKNOWLEDGMENTS}

We would like to take this opportunity to express sincerest thanks and gratitude to all people who gave their time to help us in the production of this dissertation, for their expertise and supports. Firstly, we would like to thank Professor Paul Clifford, our program instructor, for his constant support. We would also like to thank Dr. Boyi Liu here. She has given a lot of help for us in the procedure of this article's completion. Here we owe a debt of gratitude to all the members who has participated in the writing for this article, none of us could complete this article alone. 


\section{REFERENCES}

[1] General Administration of Customs, P.R. China. Goods Trade Early Harvest List of China Mainland $\begin{array}{llll}\text { in } & \text { ECFA. } & 31 & 12\end{array} 2010$. <http://www.customs.gov.cn/customs/302249/3023 10/302311/302312/hxlajjhzkjxyecfa/394889/index. html>.

[2] General Administration of Customs, P.R. China. Goods Trade Early Harvest List of Taiwan in $\begin{array}{llll}\text { ECFA. } & 31 & 12 & 2010 .\end{array}$ <http://www.customs.gov.cn/customs/302249/3023 10/302311/302312/hxlajjhzkjxyecfa/394893/index. html>.

[3] Song Xixiang, Liu Jun, Daisha. "Discussion on several issues of Cross-strait Service Trade Agreement." International Trade Law series.8.00(2018):134-153. doi:CNKI:SUN:GMFL.0.2018-00-009.

[4] Xuedang Zheng, Xiaohong Hua, "The upgrading path and strategy choices of cross-strait industrial cooperation from the perspective of global value chain",[J].Theoretical Journal, 2017(02):75-81.

[5] Lei. "Evaluation of the IMPACT OF ECFA on cross-strait economies: a simulation analysis based on GTAP model". International Trade Issues, 2012, $\{4\}(08): 22-28$.

[6] Zeng Huaqun. "ECFA: The Practice of Regional Trade Agreements with "Cross-Strait Characteristics"." Journal of Xiamen University (Philosophy and Social Sciences Edition).04(2011):78-85. doi:CNKI:SUN:XMDS.0.2011-04- 011.

[7] Yagawa," the rule system of legal coordination of cross-strait economic cooperation." Western law review,

doi:CNKI:SUN:GZCJ.0.2018-01-008.

[8] Xuan, Y. "The Complementarity of ECFA to Cross-strait Economic Cooperation and Its Special Effects". Journal of Changsha University,27.04(2013):26-29. DOI :CNKI:SUN:CSDX.0.2013-04-008.

[9] Chang, T. C. (2013). A Model or a Symbol? Criminal IP Judicial Reforms of Taiwan under US Special 301

[10] Tsung-Chen Lee and Chia-Hsuan $\mathrm{Wu}$ and Paul T.-W. Lee. "Impacts of the ECFA on seaborne trade volume and policy development for shipping and port industry in Taiwan". Maritime Policy \& Management 38.2(2011): 169-189.

[11] Xuedang Zheng, Yuren Zhang, Zhicheng Qiu, "The management and strategy adjustment of mainland Taiwan-funded enterprises after ECFA--Based on the questionnaire survey analysis of 236 Taiwan-funded manufacturing enterprises" Taiwan Research Journal.05(2017):57-68.doi:10.14157/j.cnki.twrq.2 017.05.007.

[12] Xuan, Y. "The Complementarity of ECFA to Cross-strait Economic Cooperation and Its Special Effects". Journal of Changsha University,27.04(2013):26-29. DOI :CNKI:SUN:CSDX.0.2013-04-008.

[13]Bai Guangyu, Liu Xueqin."Analysis on the effectiveness of cross-strait economic and trade cooperation in the tenth anniversary ECFA." Asia-PacificEconomics.05(2020):132-141+152.doi: 10.16407/j.cnki.1000-6052.2020.05.015. 